\title{
Social Disconnection and Living Arrangements among Older Adults: The Singapore Chinese Health Study
}

\author{
Jon Barrenetxea ${ }^{a}$ Yi Yang $^{\mathrm{a}}$ An Pan ${ }^{\mathrm{b}}$ Qiushi Feng ${ }^{\mathrm{c}}$ Woon-Puay Koh ${ }^{\mathrm{a}, \mathrm{d}}$ \\ aHealth Services and Systems Research, Duke-NUS Medical School Singapore, Singapore, Singapore; \\ ${ }^{b}$ Department of Epidemiology and Biostatistics, MOE Key Lab of Environment and Health, School of Public Health, \\ Tongji Medical College, Huazhong University of Science and Technology, Wuhan, China; 'Department of \\ Sociology \& Centre for Family and Population Research, National University of Singapore, Singapore, Singapore; \\ dHealthy Longevity Translational Research Programme, Yong Loo Lin School of Medicine, National University of \\ Singapore, Singapore, Singapore
}

\section{Keywords}

Social isolation · Social networks · Population-based design · Community-dwelling older adult · Social support

\begin{abstract}
Introduction: Although living alone is associated with social disconnection, older adults could be socially disconnected despite living with others. Understanding the factors associated with social disconnection by living arrangement could help identify vulnerable older adults in the community. We examined the sociodemographic and health factors associated with social disconnection among two groups of older adults: those living alone and those living with others. Methods: We used data from 16,943 community-dwelling older adults from the third follow-up of the Singapore Chinese Health Study (mean age: 73 years, range: 61-96 years). We defined social disconnection as having no social participation and scoring in the lowest decile on the Duke Social Support Scale of perceived social support. We ran logistic regression models to study the sociodemographic (age, gender, and education) and health (self-rated health, instrumental limitations, cognitive function, and depression) factors asso-
\end{abstract}

karger@karger.com www.karger.com/ger

Karger!"

BOPEN ACCESS
(C) 2021 The Author(s)

Published by S. Karger AG, Basel

This is an Open Access article licensed under the Creative Commons Attribution-NonCommercial-4.0 International License (CC BY-NC) (http://www.karger.com/Services/OpenAccessLicense), applicable to the online version of the article only. Usage and distribution for commercial purposes requires written permission. ciated with social disconnection, stratified by living arrangement. Results: About $6 \%$ of our participants were socially disconnected. Although living alone was significantly associated with social disconnection (OR 1.93, 95\% Cl: 1.58-2.35), $85.6 \%$ of socially disconnected older adults lived with others, most of them (92\%) with family. Lower education level, cognitive impairment, fair/poor self-rated health, instrumental limitations, and depression were independently associated with social disconnection. Among those living alone, men were more likely to experience social disconnection than women (OR 2.18, 95\% Cl: 1.43-3.32). Discussion/Conclusion: Though living alone is associated with social disconnection, most socially disconnected individuals lived with family. Community interventions could focus on those in poor health despite living with family and older men living alone.

(c) 2021 The Author(s)

Published by S. Karger AG, Basel

\section{Introduction}

Social disconnection is an umbrella term to describe the lack of social, emotional, and physical engagement with other people, which covers structural and functional
Correspondence to:

Qiushi Feng, socfq@nus.edu.sg 
measurements such as social isolation and loneliness [1]. While structural measurements of social disconnection capture objective metrics of an individual's social life such as living arrangements or network size, functional measurements are often subjective evaluations on the quality and meaning of social relationships. Among older adults, social disconnection is associated with poorer cognitive function [2], dementia [3], depression [4], disability [5], and higher mortality risk [6]. The relevance of social disconnection has been further reinforced with the ongoing COVID-19 pandemic, since social distancing measures have placed older adults at higher risk of losing social connections [7]. As the proportions of older adults increase worldwide and family sizes shrink, older adults could have fewer sources from which to draw social support and therefore be more likely to experience social disconnection in the future. Hence, identifying groups of older adults at risk of social disconnection is necessary for developing more effective interventions that fill the gaps of social support.

It is well established that older adults who live alone are at higher risk for social disconnection [8-10]. Living alone may prevent older adults from receiving immediate support, which could explain the associations between living alone and worse cognitive function [11], higher risk of unplanned hospitalizations [12], and higher mortality [13]. Consequently, interventions addressing social disconnection often target solo-living individuals as a straightforward strategy to identify vulnerable older adults $[14,15]$. While living alone is a plausible indicator to identify vulnerable people, older adults who live alone are highly heterogeneous. Although some adults living alone may be socially disconnected, others may live alone and still be socially engaged [16]. Conversely, older adults could be socially disconnected despite living with others [17]. In fact, some previous research has shown that older adults who live alone could be more socially active than those living with others $[18,19]$.

This divergence between social disconnection and living arrangements could have various underpinnings. First, according to the social selection theory, those with mental, cognitive, and physical limitations are restricted in their capacity to maintain social relationships [20-23], which could explain why older people in poor health can be socially disconnected despite living with others. In addition, good health is often the precondition for older adults to live independently [24], making those living alone more likely to engage in social activities. Second, individuals could differ in social interactions regardless of living arrangements due to personality, coping mech-

Social Disconnection and Living

Arrangements anisms, and many other psychological propensities [16]. Cultural norms may also increase or decrease the risk of social disconnection for certain living arrangements. Among older adults living alone, the risk of social disconnection could be lower in societies where freedom and privacy in old ages are appreciated. Conversely, in societies that promote strong family support and multigenerational coresidence, living alone could increase the risk of social disconnection because of the expected closeness and frequency of family interactions [25]. Given the complex relationship between living arrangements and social disconnection, living alone may not be a robust indicator to identify older adults at risk of social disconnection. If community interventions do not uncouple social disconnection from living alone, the extent of social disconnection in the community could be underestimated. This could result in misallocation of resources because social disconnection is not properly characterized.

The relationship between social disconnection and living arrangements is particularly complex in Asia, where multigenerational coresidence is common. Although Western older adults tend to pursue independence in later life, Asian older adults are bound to their adult children by cultural norms of filial piety that demand coresidence and strong family support [26]. Additionally, Western older adults rely more on state-sponsored welfare and social support beyond family, whereas the support sources of Asian older adults are mostly restricted to close family members [27]. Thus, covariates of social disconnection may vary markedly with living arrangements in Asia. For example, it has been observed that older adults living alone tend to be functionally independent and have more diverse networks of support, while those living with family often have poorer health and less social ties beyond family $[28,29]$.

Moreover, as older adults are predominantly cared for by coresiding family members in Asia, older people living alone are often considered a disadvantaged group and thus the target of policy interventions. This leads to the problematic assumption that older people living with family are at comparatively less risk of social disconnection. However, living with family may not necessarily translate into sufficient social engagement and meaningful interactions to avoid social disconnection. Social selection due to health problems could pose a higher risk of social disconnection among those living with others than among those living alone. Conversely, cultural factors promoting family coresidence as the normative living arrangement could place those living alone at higher risk of 
social disconnection than those living with others. Hence, both older adults living with others and older adults living alone could experience social disconnection, albeit for different reasons. Therefore, in the cultural context of Asia, it is necessary to examine the factors associated with social disconnection by living arrangement.

Singapore is a city-state in Southeast Asia with shrinking household sizes and a rising proportion of older adults [30]. While recent trends show a steady increase in 1-person households and a growing preference for living independently in the community, only $9 \%$ of older adults live alone, indicating a strong sense of familialism in the society [31]. In the public policy, the government promotes family as the first line of support for older adults, followed by support from the wider community, such as friends, voluntary welfare organizations, and other social groups [32]. The majority of older adults live with a spouse and/ or children and draw support mainly from family. This is particularly the case for older adults with health problems [28]. As a result, older adults who live alone are considered disadvantaged and thus become the primary recipients for government assistance, which aims to cover the gap in family support with a wide range of services such as befriending activities, instrumental help, day care at senior activity centers, and subsidies for assistive devices to remain ambulant in the community [33].

Using a cohort of community-dwelling older adults in Singapore, we aimed to uncouple social disconnection from living arrangements by studying the factors associated with social disconnection among older adults who live alone and older adults who live with others. We operationalized social disconnection as scoring in the lowest decile on the Duke Social Support Scale (DUSOCS) of perceived social support and having no social participation in group activities outside the household. We first studied the factors associated with social disconnection in the overall sample. We then ran an interaction analysis to identify associations modified by living arrangement status. Finally, we stratified the analysis by living arrangements and studied the factors associated with social disconnection among older adults living alone and older adults living with others. Given that most older adults in Singapore live in multigenerational households, we expect living alone to be associated with social disconnection because of cultural expectations for intergenerational coresidence. However, we also consider that older adults in poor health who live with family could be at risk of social disconnection because of their possible difficulties maintaining social relationships outside of the household.

\section{Materials and Methods}

\section{Study Participants}

The Singapore Chinese Health Study (SCHS) is a populationbased cohort of 63,275 Singaporean Chinese aged 45-74 years at the time of recruitment (1993-1998). It is an ongoing prospective cohort study designed to evaluate the genetic, dietary, and environmental determinants of chronic diseases in Chinese adults living in Singapore [34]. Participants were recruited from residents living in government-built housing estates, where $86 \%$ of Singaporeans resided at that time. After the baseline interview, consenting participants were recontacted for the first follow-up (19992004, $N=52,322)$, second follow-up (2006-2010, $N=39,528)$, and third follow-up $(2014-2016, N=17,107)$ interviews for updates on lifestyle factors and medical history. In addition, the third followup included measurements on aging outcomes such as cognitive function, instrumental limitations, depression, and social support. All participants gave written informed consent. This study was approved by the Institutional Review Board of the National University of Singapore (Approval No. NUS 2108).

In this study, we used data obtained from the third follow-up interviews, which were administered by trained interviewers in person for 17,107 surviving participants aged 61-96 years (mean age of 73 years) from 2014 to 2016 . Women accounted for $59.2 \%$ of the sample, and only $36.4 \%$ of participants achieved secondary education. After excluding participants with missing values on the cognitive test $(n=55)$ and self-rated health $(n=2)$ and who were mute $(n=1)$, blind $(n=55)$, deaf $(n=48)$, or living in nursing homes $(n=3)$, this study included 16,943 participants $(6,912$ men and 10,031 women).

\section{Assessment of Social Disconnection}

Most older adults in Singapore live and frequently interact with family members. Hence, to operationalize social disconnection, we used measurements that emphasize quality of social interactions over quantity and considered gatherings beyond the family network. We therefore defined social disconnection as scoring in the lowest decile on the Duke Social Support Scale (DUSOCS) of perceived social support and having no social participation in group activities outside the household. Both conditions must be met to be considered socially disconnected.

The DUSOCS defined perceived social support as "having someone who is helpful, who will listen to you, or who will back you up when you are in trouble" and measures the amount of support in 4 different levels: "none," "some," "a lot," and "there is no such person." The scale identified 6 sources of family support (partners, children/grandchildren, parents, siblings, other relatives, and relatives by marriage) and 4 sources of nonfamily support (neighbors, coworkers, religious group members, and friends). The questionnaire also asked if there was a special supportive person, that is, a "particular person whom you trust and to whom you can go with personal difficulties." The scores were then summated to compute the total social support score, which ranged from 0 (no support) to 100 (most support) [35].

Social participation was assessed with this question: "How many hours each week do you participate in any groups ( $\geq 3$ people) such as a social or work group, church-connected group, selfhelp group, charity, public service, or community group?" Those with $<1 \mathrm{~h}$ of social participation per week were considered as having "no social participation." 
Table 1. Characteristics of study participants according to social disconnection status, the Singapore Chinese Health Study

\begin{tabular}{|c|c|c|c|}
\hline & Total & $\begin{array}{l}\text { Not socially } \\
\text { disconnected }\end{array}$ & $\begin{array}{l}\text { Socially } \\
\text { disconnected }\end{array}$ \\
\hline \multicolumn{4}{|l|}{ Living arrangements, $n(\%)$} \\
\hline Living with family (spouse/children) & $14,917(88.0)$ & $14,113(88.6)$ & $804(78.8)$ \\
\hline Living with other relatives/friends & $705(4.2)$ & $635(4.0)$ & $70(6.8)$ \\
\hline Living alone & $1,321(7.8)$ & $1,174(7.4)$ & $147(14.4)$ \\
\hline Mean age (SD), years & $73.2(6.41)$ & $73.0(6.38)$ & $75.5(6.51)$ \\
\hline \multicolumn{4}{|l|}{ Gender, $n(\%)$} \\
\hline Women & $10,030(59.2)$ & $9,356(58.8)$ & $674(66.0)$ \\
\hline Men & $6,913(40.8)$ & $6,566(41.2)$ & $347(34.0)$ \\
\hline \multicolumn{4}{|l|}{ Education level, $n(\%)$} \\
\hline Secondary and above & $6,167(36.4)$ & $5,981(37.6)$ & $186(18.2)$ \\
\hline Primary & $7,586(44.8)$ & $7,115(44.7)$ & $471(46.1)$ \\
\hline No formal education & $3,190(18.8)$ & $2,826(17.7)$ & $364(35.7)$ \\
\hline \multicolumn{4}{|l|}{ Instrumental limitations, $n(\%)$} \\
\hline None & $12,428(73.4)$ & $11,809(74.2)$ & $619(60.6)$ \\
\hline At least one & $4,515(26.6)$ & $4,113(25.8)$ & $402(39.4)$ \\
\hline \multicolumn{4}{|l|}{ Self-rated health, $n(\%)$} \\
\hline Good/very good/excellent & $8,290(48.9)$ & $7,883(49.5)$ & 407 (39.9) \\
\hline Fair/poor & $8,653(51.1)$ & $8,039(50.5)$ & $614(60.1)$ \\
\hline \multicolumn{4}{|l|}{ Cognitive function, $n(\%)$} \\
\hline Not cognitively impaired & $14,504(85.6)$ & $13,754(86.4)$ & $750(73.5)$ \\
\hline Cognitively impaired & $2,439(14.4)$ & $2,168(13.6)$ & $271(26.5)$ \\
\hline \multicolumn{4}{|l|}{ Depression, $n(\%)$} \\
\hline Not depressed & $12,458(73.5)$ & $11,973(75.2)$ & 485 (47.5) \\
\hline Depressed & $4,485(26.5)$ & $3,949(24.8)$ & $536(52.5)$ \\
\hline
\end{tabular}

\section{Sociodemographic and Health Factors}

Based on living arrangements, we categorized participants as living alone or living with others. Among those living with others, participants lived either with family (spouse, children, or spouse and children) or with other relatives/friends. We also included additional sociodemographic factors such as age (years), gender, and education level (no formal education, primary school, and secondary school and above). As health factors, we measured self-rated health using the question "In general, would you say your health is: "excellent," "very good," "good," "fair," or "poor"? We assessed the ability to perform tasks using the Lawton instrumental activities of daily living scale (IADL) [36]. We rated each item dichotomously and computed summary scores from 0 (low function) to 8 (high function). Respondents were classified as those with no instrumental limitations (score of 8 ) and those with at least 1 instrumental limitation (score $<8$ ). We also measured depression using the Geriatric Depression Scale (GDS) scores, and being depressed was defined as having GDS scores of 5 or higher [37]. Cognitive function was determined using a modified Singapore version of the Mini-Mental State Examination (MMSE) [38]. Since our participants had relatively low educational level, we defined cognitive impairment using education-specific cutoff points of $<18$ for those without formal schooling, $<21$ for those with $1-6$ years of education, and $<25$ for those with $>6$ years of education [39].

Social Disconnection and Living

Arrangements

\section{Statistical Analysis}

We first studied the factors associated with social disconnection in the overall sample using multiple variable logistic regression. We then ran an interaction analysis in the overall sample to identify associations modified by living arrangement status. We tested interactions by adding the cross product of each sociodemographic/ health factor and living arrangement and extracted the $p$ value of the interaction term. Finally, we stratified the analysis by living arrangements and studied the factors associated with social disconnection among older adults living alone and older adults living with others. All statistical analyses were conducted using Stata Statistical Software, Release 14.0 (StataCorp, College Station, TX, USA) with 2 -sided $p$ value $<0.05$ as the threshold for statistical significance.

\section{Results}

About $88 \%$ of participants lived with family comprising spouse and/or children. Half of the participants had poor/fair self-rated health and $26.6 \%$ reported at least 1 instrumental limitation. Using education-specific cutoff points for MMSE scores, $14.4 \%$ of the participants were categorized as cognitively impaired. Similarly, GDS 
scores indicated that $26.5 \%$ of the participants were depressed. About $6 \%$ of the participants were socially disconnected. Among them, $85.6 \%$ lived with others, of which $92 \%$ lived with family. Socially disconnected participants were older and more likely to be women. They had lower levels of education and higher prevalence of instrumental limitations, poor self-rated health, cognitive impairment, and depression than those who were not socially disconnected (Table 1).

Although only $14.4 \%$ of socially disconnected participants lived alone, living alone remained a significant risk factor for social disconnection after adjusting for health and sociodemographic factors (OR 1.93, 95\% CI: 1.582.35). Lower education was associated with increased odds of social disconnection in a stepwise manner ( $p$ for trend $<0.001$ ). In addition, instrumental limitations (OR $1.16,95 \%$ CI: $1.00-1.34$ ), poor self-rated health (OR 1.14 , 95\% CI: 1.00-1.31), cognitive impairment (OR 1.73, 95\% CI: 1.46-2.04), and depression (OR 2.43, 95\% CI: $2.11-$ 2.80) were also factors associated with social disconnection in our cohort (Table 2).

In analysis stratified by living arrangement, the associations between the aforementioned factors and the odds of social disconnection were not significantly different between those living alone and those living with others except for 2 factors. First, although education level followed a dose-response relationship regardless of living arrangements ( $p$ for trend $<0.001$ ), lower or no formal education was associated with higher odds of social disconnection in those living with others compared to those living alone ( $p$ for interaction $=0.039$ ). Second, compared to women, men had a higher risk of social disconnection among those living alone (OR 2.18, 95\% CI: 1.43-3.32), but not among those living with others (OR 0.99, 95\% CI: $0.84-1.17)$ ( $p$ for interaction $<0.001$ ) (Table 3$)$.

\section{Discussion/Conclusion}

In this study among community-dwelling Singaporean older adults, although living alone remained a significant risk factor for social disconnection, about $78.8 \%$ of socially disconnected older adults lived with family. Lower education level, cognitive impairment, poor selfrated health, instrumental limitations, and depression were independently associated with social disconnection. Among those living alone, men were more likely to experience social disconnection than women.

The proportion of social disconnection in our cohort (6\%) was lower than that reported in other international
Table 2. Sociodemographic and health factors associated with social disconnection, the Singapore Chinese Health Study

Odds ratio $(95 \% \mathrm{CI})^{\circ}$

$\begin{array}{ll}\text { Living arrangement } & \\ \quad \text { Living with others } & 1.00 \\ \quad \text { Living alone } & 1.93(1.58-2.35) \\ \text { Gender } & 1.00 \\ \quad \text { Women } & 1.09(0.93-1.27) \\ \quad \text { Men } & \\ \text { Education level } & \\ \quad \text { Secondary and above } & 1.00 \\ \quad \text { Primary } & 1.79(1.49-2.14) \\ \quad \text { No formal education } & 2.91(2.35-2.60) \\ \text { Instrumental limitations } & \\ \quad \text { None } & 1.00 \\ \text { At least one } & 1.16(1.00-1.34) \\ \text { Self-rated health } & 1.00 \\ \quad \text { Good/very good/excellent } & 1.14(1.00-1.31) \\ \text { Poor/fair } & \\ \text { Cognitive function } & 1.00 \\ \quad \text { Not cognitively impaired } & 1.73(1.46-2.04) \\ \quad \text { Cognitively impaired } & \\ \text { Depression } & 1.00 \\ \quad \text { Not depressed } & 2.43(2.11-2.80) \\ \quad \text { Depressed } & \end{array}$

○ Adjusted for living arrangement, age, gender, education, instrumental limitations, self-rated health, cognitive function, and depression. ${ }^{\dagger} p$ value for linear effect $<0.001$. The test examined if the association between education level and social disconnection follows a linear dose-response relationship.

studies using varying definitions of social disconnection $[40,41]$. Therefore, our results suggest that most older people in Singapore are socially connected and receive enough social support in the community. This could be explained by the multipronged efforts from the government to support older adults, using family as the first line of support and the extended community as the second line of support [32]. In this context, older adults who live alone and have no support from immediate family are the main target for government assistance. This could explain why only $14.4 \%$ of participants living alone were socially disconnected. On the other hand, the fact that $78.8 \%$ of socially disconnected individuals lived with family shows that cohabitation does not necessarily ensure enough social support to avoid social disconnection. Hence, community interventions could shift their focus from older adults living alone to older adults who live with their family but who are in poor health. Otherwise, the extent of social disconnection among older adults in the community could be underestimated. 
Table 3. Sociodemographic and health factors associated with social disconnection according to living arrangement, the Singapore Chinese Health Study

\begin{tabular}{|c|c|c|c|}
\hline & $\begin{array}{l}\text { Living with others, OR } \\
(95 \% \text { CI })^{\circ}\end{array}$ & $\begin{array}{l}\text { Living alone, OR } \\
(95 \% \mathrm{CI})^{\circ}\end{array}$ & $\begin{array}{l}p \text { value for } \\
\text { interaction }\end{array}$ \\
\hline \multicolumn{4}{|l|}{ Gender } \\
\hline Women & 1.00 & 1.00 & \multirow{2}{*}{$<0.001$} \\
\hline Men & $1.00(0.85-1.17)$ & $2.18(1.43-3.32)$ & \\
\hline \multicolumn{4}{|l|}{ Education level ${ }^{\ddagger}$} \\
\hline Secondary and above & 1.00 & 1.00 & \multirow{3}{*}{0.039} \\
\hline Primary & $1.90(1.56-2.32)$ & $1.17(0.73-1.87)$ & \\
\hline No formal education & $2.95(2.33-3.73)$ & $2.46(1.46-4.16)$ & \\
\hline \multicolumn{4}{|l|}{ Instrumental limitations } \\
\hline None & 1.00 & 1.00 & \multirow{2}{*}{0.085} \\
\hline At least one & $1.19(1.01-1.40)$ & $0.89(0.57-1.38)$ & \\
\hline \multicolumn{4}{|l|}{ Self-rated health } \\
\hline Good/excellent & 1.00 & 1.00 & \multirow{2}{*}{0.612} \\
\hline Poor/fair & $1.10(0.95-1.27)$ & $1.47(1.01-2.13)$ & \\
\hline \multicolumn{4}{|l|}{ Cognitive function } \\
\hline Not cognitively impaired & 1.00 & 1.00 & \multirow{2}{*}{0.813} \\
\hline Cognitively impaired & $1.67(1.40-2.00)$ & $1.96(1.25-3.07)$ & \\
\hline \multicolumn{4}{|l|}{ Depression } \\
\hline Not depressed & 1.00 & 1.00 & \multirow{2}{*}{0.072} \\
\hline Depressed & $2.54(2.18-2.96)$ & $2.01(1.40-2.90)$ & \\
\hline
\end{tabular}

OR, odds ratio; CI, confidence interval. ${ }^{\circ}$ Adjusted for age, gender, education, instrumental limitations, selfrated health, cognitive function, and depression. $\uparrow$ Calculated by adding the cross product of each factor and living arrangements to the full sample model $(N=16,943) .{ }^{*} p$ value for linear effect $<0.001$ for either the model of living alone or living with others. The tests examined if the association between education level and social disconnection follows a linear dose-response relationship.

Although only $14.4 \%$ of those with social disconnection lived alone in our study, living alone remained a significant risk factor for social disconnection, which concurs with previous studies [8-10]. Our study also revealed additional risk factors for social disconnection among community-dwelling Singaporean older adults. The inverse dose-response relationship between social disconnection and education level is expected. Individuals with higher education levels have more exposure to diverse social networks and are more likely to retain more social connections, thereby feeling less disconnected in later life [42]. Likewise, the higher risk for social disconnection among individuals with depression, cognitive impairment, instrumental limitations, and poor self-rated health is in line with the social selection theory, which argues that poor health could affect social engagement and lead to less social support [20].

Remarkably, stratified analysis by living arrangement showed that among older adults who lived alone, men were twice more likely to be disconnected than women. These results concur with previous studies that under- score the vulnerability of older men living alone $[5,12]$. Given their traditional role as wage earners, men have smaller social networks and report less social interactions than women [40]. In addition, transitioning from employment to retirement could further curtail their social network and increase their social disconnection. Interestingly, stratified analysis also revealed that those with instrumental limitations and depression while living with others could have higher risk of social disconnection than their counterparts living alone, although the difference in the odds ratios between these groups did not reach statistical significance. This could be explained by differences in expectations between those living alone and those living with family. Among older adults with functional dependence, those who lived with family could have high expectations of support from their household members, which could, in turn, lead to feelings of social disconnection when the expected support is not available [43]. In addition, older adults living with others may be restricted to household members to cover their instrumental, emotional, and social needs, whereas those living alone can rely on more 
diverse networks of support that specialize in covering specific needs [44]. For example, those living alone could resort to friends or neighbors to cover their social/emotional needs while relying on family for instrumental/financial support. Such optimization of support resources among those living alone could attenuate the association between instrumental limitations and depression with social disconnection compared to those living with others.

The results presented here hold policy-relevant implications to refine community interventions in terms of target population and design. Rising proportions of older adults, shrinking family sizes, and possible outbreaks of pandemics such as COVID-19 will further expose older people to living without family companions and social interactions. In this context, identifying individuals at higher risk of social disconnection is key to designing effective interventions and optimizing allocation of resources. Currently, interventions addressing social disconnection in Singapore and internationally mostly rely on befriending activities to increase social engagement among older adults living alone $[14,33]$. However, our results show that most socially disconnected older adults in Singapore actually live with others, the majority of them with family. Hence, interventions could extend their scope to include older adults living with family, particularly those in poor health. This could mean improving the quality of interactions with their family and involving extended members of the community (friends and neighbors) for regular social interactions. As for those who live alone, our study has found that men are at higher risk of social disconnection than women. This could help adapt interventions to the social world of older men who live alone, based on their willingness to engage in social activities and the persistence of their social disconnection [16].

The strengths of this study are its population-based design, the use of validated instruments to define social disconnection, and the large sample size, which allows for stratified analysis by living arrangements. Nevertheless, there are some limitations. First and foremost, it was a cross-sectional study, and therefore we could not determine the directionality of the association between social disconnection and health factors. While most studies use social disconnection as a predictor of poor health, poor health can also limit social engagement and lead to social disconnection [20]. Hence, the relationship between social disconnection and health is complex, and longitudinal data are required to elucidate the directionality of this relationship.

Second, the definition of social disconnection based on perceived social support and social participation may not be comparable to other studies using alternative measures of social disconnection (such as social network size). However, we argue that operationalization of social disconnection used in this study is tailored to the Asian context. While objective measurements of social disconnection such as frequency of social interactions or size of social networks could be effective in Western samples, they may not be useful in Asia because older adults interact frequently and often live with family. Therefore, subjective measurements such as perceived support and social interactions outside the household may be more suitable to identify older adults at risk of social disconnection in Asia.

Third, the DUSOCS was not adapted to the Singaporean context. Items that could be irrelevant to a retired elderly population such as "parents" and "coworkers" were kept, whereas foreign domestic workers, who are important caregivers for older adults in Singapore, were not included in the questionnaire. Finally, our study only included community-dwelling older adults of Chinese ethnicity, which comprise $74.4 \%$ of the population in Singapore [30]. Since Malays, Indians, and other ethnicities were not considered here, the results may not be generalizable to socioeconomically, culturally, and ethnically diverse populations.

In conclusion, though living alone was associated with social disconnection, most socially disconnected individuals in the community lived with family. Additional factors associated with social disconnection were lower education level, cognitive impairment, fair/poor self-rated health, instrumental limitations, and depression, which could be used to help identify older adults in need of support more effectively. Our study recommends focusing community interventions on men who live alone and extending their scope to older adults in poor health despite living with family.

\section{Acknowledgment}

We thank Ms. Siew-Hong Low of the National University of Singapore for supervising the fieldwork of the Singapore Chinese Health Study.

\section{Statement of Ethics}

All participants gave written informed consent. This study was approved by the Institutional Review Board of the National University of Singapore (Approval No. NUS 2108).

\section{Conflict of Interest Statement}

The authors have no conflicts of interest to declare. 


\section{Funding Sources}

This work was supported by the National Medical Research Council, Singapore (NMRC/CSA/0055/2013); National Cancer Institute, National Institutes of Health, USA (Grant No. UM1 CA182876 and R01 CA144034); and the Saw Swee Hock School of Public Health, National University of Singapore. Woon-Puay Koh is supported by the National Medical Research Council, Singapore (MOH-CSASI19nov-0001).

\section{Author Contributions}

W.-P. Koh, A. Pan, and Q. Feng designed and conducted the study. J. Barrenetxea and Y. Yang analyzed the data. Q. Feng and W.-P. Koh assisted in interpreting the data. J. Barrenetxea wrote the first draft, and all authors critically edited the manuscript. All authors read and approved the final manuscript.

\section{References}

1 Holt-lunstad J. Why social relationships are important for physical health : a systems approach to understanding and modifying risk and protection. Annu Rev Psychol. 2018;69: 437-58.

2 Shankar A, Hamer M, McMunn A, Steptoe A. Social isolation and loneliness: relationships with cognitive function during 4 years of follow-up in the English Longitudinal Study of Ageing. Psychosom Med. 2013;75:161-70.

3 Penninkilampi R, Casey AN, Singh MF, Brodaty $\mathrm{H}$. The association between social engagement, loneliness, and risk of dementia: a systematic review and meta-analysis. J Alzheimers Dis. 2018;66(4):1619-33.

4 Schwarzbach M, Luppa M, Forstmeier S, König HH, Riedel-heller SG. Social relations and depression in late life-a systematic review. Int J Geriatr Psychiatry. 2014;29(1):121.

5 Gale CR, Westbury L, Cooper C. Social isolation and loneliness as risk factors for the progression of frailty : the English Longitudinal Study of Ageing. Age Ageing. 2018;47(3): 392-7.

6 Holt-lunstad J, Smith TB, Baker M, Harris T, Stephenson D. Loneliness and social isolation as risk factors for mortality : a meta-analytic review. Perspect Psychol Sci. 2015;10(2):22737.

7 Cudjoe TKM, Kotwal AA. "Social distancing" amid a crisis in social isolation and loneliness. J Am Geriatr Soc. 2020;68(6):E27.

8 Cacioppo JT, Hawkley LC. Social isolation and health, with an emphasis on underlying mechanisms. Perspect Biol Med. 2003;46(3 Suppl 1):S39.

9 Holt-lunstad J. The potential public health relevance of social isolation and loneliness : prevalence, epidemiology, and risk factors. Public Policy Aging Rep. 2018;27(4):127-30.

10 Victor C, Scambler S, Bond J, Bowling A. Being alone in later life: loneliness, social isolation and living alone. Rev Clin Gerontol. 2000;10(4):407-17.

11 Grande G, Vetrano DL, Cova I, Pomati S, Mattavelli D, Maggiore L, et al. Living alone and dementia incidence: a clinical-based study in people with mild cognitive impairment. J Geriatr Psychiatry Neurol. 2018; $31(3): 1-7$
12 Pimouguet C, Rizzuto D, Lagergren M, Fratiglioni $\mathrm{L}, \mathrm{Xu} \mathrm{W}$. Living alone and unplanned hospitalizations among older adults : a population-based longitudinal study. Eur J Public Health. 2016;27(2):251-6.

13 Ng TP, Jin A, Feng L, Shwe M, Nyunt Z, Chow $\mathrm{KY}$, et al. Mortality of older persons living alone : Singapore Longitudinal Ageing Studies. BMC Geriatr. 2015;15:126.

14 Rourke HMO, Collins L, Sidani S. Interventions to address social connectedness and loneliness for older adults : a scoping review. BMC Geriatr. 2018;18(214):1-13.

15 Kharicha K, Iliffe S, Harari D, Swift C, Gillmann G, Stuck AE. Health risk appraisal in older people 1 : are older people living alone an "at-risk" group ? Br J Gen Pract. 2007; 57(537):271-6.

16 Machielse A. The heterogeneity of socially isolated older adults : a social isolation typology. J Gerontol Soc Work. 2015;58(4):33856.

$17 \mathrm{Hsu} \mathrm{H}$. Typologies of loneliness, isolation and living alone are associated with psychological well-being among older adults in Taipei : a cross-sectional study. Int J Environ Res Public Health. 2020;17(24):9181.

18 Mair CA. Alternatives to aging alone ?: "Kinlessness" and the importance of friends across European contexts. J Gerontol B Psychol Sci Soc Sci. 2019;74(8):1416-28.

19 Djundeva M, Dykstra PA, Fokkema T. Is living alone "Aging Alone"? solitary living, network types, and well-being. J Gerontol B Psychol Sci Soc Sci. 2019;74(8):1406-15.

20 Johnson TP. Mental health, social relations, and social selection : a longitudinal analysis. J Health Soc Behav. 1991;32(4):408-23.

21 Liao J, Muniz-terrera G, Head J, Brunner EJ. Dynamic longitudinal associations between social support and cognitive function : a prospective investigation of the directionality of associations. J Gerontol Psychosoc Sci. 2018; 73(7):1233-43.

22 Sirven N, Debrand T. Social capital and health of older Europeans: causal pathways and health inequalities. Soc Sci Med. 2012;75: 1288-95.

23 Cornwell B. Good health and the bridging of structural holes. Soc Networks. 2009;31(1): 92-103.
24 Gu D, Feng Q, Yeung WJ. Reciprocal dynamics of solo-living and health among older adults in contemporary China. J Gerontol B Psychol Sci Soc Sci. 2018;74(8):1441-52.

25 Russell D, Taylor J. Living alone and depressive symptoms: the influence of gender, physical disability, and social support among hispanic and non-hispanic older adults. J Gerontol Soc Sci. 2009;64B(1):95-104.

26 Yeh K, Yi C, Tsao W, Wan P. Filial piety in contemporary Chinese societies : a comparative study of Taiwan, Hong Kong, and China. Int Sociol. 2013;28(3):277-96.

27 Cheng C. Anticipated support from children and later-life health in the United States and China. Soc Sci Med. 2017;179:201-9.

28 Barrenetxea J, Yang Y, Markides KS, Pan A, Koh W-P, Feng Q. Social support and health among older adults: the Singapore Chinese Health Study. Ageing Soc. 2021:1-17.

29 Gu D, Feng Q, Yeung WJ. Reciprocal dynamics of solo-living and health among older adults in contemporary China. J Gerontol B Psychol Sci Soc Sci. 2018;74(8):1441-52.

30 Department of Statistics. Population trends, 2019. Republic of Singapore; 2019.

31 Linton E, Gubhaju B, Chan A. Home alone: older adults in Singapore. Research Brief Series 4.. Singapore: Centre for Ageing Research and Education (CARE); 2018. p. 1-13.

32 Thang LL, Johan S. Growing old in Singapore. Ageing in asia-pacific: interdisciplinary and comparative perspectives. 1st ed New York: Routledge; 2018. p. 131-52.

33 Agency for integrated care. Community of care: 2018 Yearbook; 2019.

34 Hankin JH, Stram DO, Arakawa K, Park S, Low S, Lee H, et al. Singapore Chinese Health Study : development, validation, and calibration of the quantitative food frequency questionnaire. Nutr Cancer. 2001;39(2):187-95.

35 Parkerson GR. Duke Social Support and Stress Scale (DUSOCS). Encyclopedia of quality of life and well-being research. Springer Netherlands; 2014. p. 1720-3.

36 Lawton MP, Brody EM. Assessment of older people: self-maintaining and instrumental activities of daily living. Gerontologist. 1969; 9(3):179-86 
37 Shwe M, Nyunt Z, Fones C, Niti M, Ng T. Criterion-based validity and reliability of the $\mathrm{Ge}$ riatric Depression Screening Scale (GDS-15) in a large validation sample of communityliving Asian older adults. Aging Ment Health. 2009; 13(3):376-82.

38 Feng L, Chong MS, Lim WS, Ng TP. The modified mini-mental state examination test: normative data for Singapore Chinese older adults and its performance in detecting early cognitive impairment. Singapore Med J.2012; 53(7):458-62.
39 Katzman R, Zhang M, Ouang YQ, Zhengyu W, Liu W, Yu E, et al. A Chinese version of the mini-mental state examination: impact of illiteracy in a Shanghai Dementia Survey. J Clin Epidemiol. 1988;41(10):971-8.

40 Cudjoe TKM, Roth DL, Szanton SL, Wolff JL, Boyd CM, Thorpe RJ. The epidemiology of social isolation: National Health and Aging Trends Study. J Gerontol B Psychol Sci Soc Sci. 2020;75(1):107-13.

41 Nicholson NR. A review of social isolation: an important but underassessed condition in older adults. J Prim Prev. 2012;33:137-52.
42 Fischer CS, Beresford L. Changes in support networks in late middle age : the extension of gender and educational differences. J Gerontol B Psychol Sci Soc Sci. 2015;70(1):123-31.

43 Johnson DP, Mullins LC. Growing old and lonely in different societies: toward a comparative perspective. J Cross Cult Gerontol. 1987; 2:257-75.

44 Poulin J, Deng R, Ingersoll TS, Witt H, Swain M. Perceived family and friend support and the psychological well-being of American and Chinese elderly persons. J Cross Cult Gerontol. 2012;27(27):305-17. 